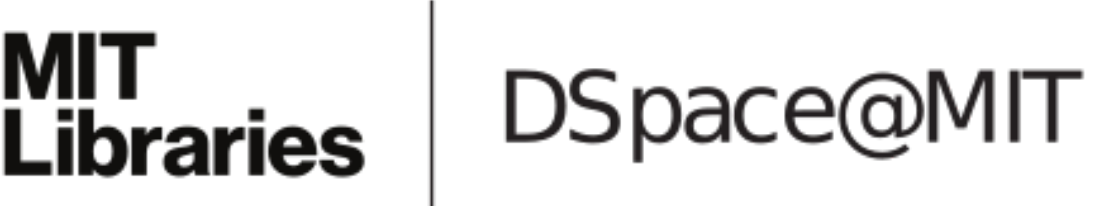

\author{
MIT Open Access Articles
}

This is a supplemental file for an item in DSpace@MIT

Item title: Materials selection considerations for high entropy alloys

Link back to the item: https://hdl.handle.net/1721.1/123689 


\title{
Materials Selection Considerations for High Entropy Alloys
}

\author{
X Fu, CA Schuh, EA Olivetti \\ Department of Materials Science and Engineering, Institute of Technology, 77 Massachusetts Avenue, \\ Cambridge, MA 02139, USA
}

\begin{abstract}
Increased interest in high entropy alloys (HEA)s has led to significant activity in the development of new equimolar multicomponent metal systems. The present viewpoint article suggests applying a lens of practicality related to alloy economics and resource usage issues. A framework for HEA materials selection is presented to assist the metallurgical community as it searches for HEAs with feasible implementation possibilities, by identifying unsuitable alloying elements based on price or metrics of supply availability. For some metrics, such as price volatility, the elemental diversification in HEAs could prove beneficial, while for others, such as recyclability, elemental breadth introduces significant challenges.
\end{abstract}

Keywords: High-entropy alloys, multicomponent, modeling, analytical methods

\section{Introduction}

The concept of high entropy alloys (HEA)s has ignited renewed interest in fundamental thermodynamics, processing, and characterization approaches for multicomponent alloys. In just a decade, the literature on high entropy alloys has increased 500 fold, as the community debates what defines an HEA and what properties can be obtained from equi-proportion combinations of multiple components that may or may not exhibit high configurational entropy [1]. Recent interest in HEA has covered a significant space of characterization and processing approaches [2], theoretical work leveraging ab initio methods to screen for promising alloys [3], and statistical approaches to mine for promising properties [4, 5]. Most HEA research focuses on two main compositional domains, namely those based on refractory elements and those based on commodity metals. The latter typically involve metals such as $\mathrm{Cr}, \mathrm{Co}, \mathrm{Fe}, \mathrm{Ni}, \mathrm{Mn}$, and $\mathrm{Cu}$, and the resulting $\mathrm{HEAs}$ are often compared with stainless steel [6]. The former use metals such as $\mathrm{V}, \mathrm{Cr}, \mathrm{Ti}, \mathrm{Mo}, \mathrm{Nb}, \mathrm{Ta}, \mathrm{W}, \mathrm{Zr}$, and $\mathrm{Hf}$ and are compared with refractory metals $[7,8]$. The compound forming elements $\mathrm{Al}$ and Ti are often added to both families [9].

Missing from these discussions to date is a quantitative framework to evaluate the feasibility of scale-up and manufacture of potential HEAs. Such a framework could help focus the space in a manner reminiscent of how Ashby charts focused the process of materials selection for mechanical design [10]. This article takes the initial steps towards such a framework for resource-efficiency evaluation applied to HEAs. In addition to structural or functional properties, price, manufacturability, and resource use are key features that should be considered; this paper presents some initial discussion on each of these points. This evaluation is fundamentally different for HEAs compared with conventional alloys because HEAs lack a base metal. An HEA has significant concentrations of five or more elements, so that even a basic metallurgical palette of 12 elements gives 3302 different HEA bases, motivating the need for intelligent ways to reduce the selection space. 
We frame this analysis from two different quantitative perspectives. First, we perform elemental screening on material price, price volatility, and resource availability (geographic concentration and coupled production). We also present analysis of these metrics once the constituent elements are mixed into a multi-component alloy. Finally, we comment on the recyclability of these materials based on the thermodynamics of separation. For some of these metrics the equi-molar concept provides a stabilizing effect, while for others the impact is negative. Through this analysis we illustrate several practical considerations that should factor into HEA design.

\section{Analysis}

In what follows, we provide commentary on material price, price volatility, materials availability, and recyclability metrics to address the potential for HEAs to compete successfully with incumbent alloys. For each metric, we first provide the method used in the analysis followed by the results for that metric. For the present analysis, we limit the discussion to equimolar alloys only, although in some cases the lessons of this analysis argue for a significant departure from that recipe in future HEA design. We emphasize that while metrics of economics, materials availability, and recyclability should ultimately be considered as part of dynamic systems whose values would be influenced by each other (correlated), the present general static framework can be applied to inform element selection and HEA design.

\section{Material price}

We first provide insight into materials price as a metric for HEA feasibility. Only material price was considered for a proposed HEA (we do not add costs incurred in processing), and we consider published materials price, rather than cost, so that we can refer to publicly available information. It is important to remember that a manufacturer incurs a cost, rather than a price, but for the purposes of describing our data and methods, one can envision the price as contributing to an incurred manufacturing cost relative to incumbent alloys.

When available, we used prices for commodity metals traded on the London Metal Exchange (LME) available from Thomson Reuters Datastream, as these are updated monthly ( $\mathrm{Ni}, \mathrm{Al}, \mathrm{Cu}, \mathrm{Zn}, \mathrm{Sn}, \mathrm{Fe}, \mathrm{Ag}, \mathrm{Au}, \mathrm{Ir}, \mathrm{Pd}$, and Pt). Otherwise, annual price data were obtained from the United States Geological Survey (USGS) historical statistics for mineral and material commodities [11] from 1964 to 2014. For metals not reported on the LME, we note some limitations in the available price data. For example, prices for some minor metals ( $\mathrm{Nb}$ and $\mathrm{Sc}$, for example) remain constant for several years because there are not data available from open transactions. Another example of a data limitation is found for the case of $Y$; the reported price was based on metal oxides before the year 2000 , but the basis for reporting changed into pure metals afterwards.

First, we categorize the elements that have been mentioned across the HEA literature of the last decade in terms of 50 year historic average price of the element. We will refer to these categories for the subsequent analysis of materials price and price volatility. These can be broken down in the following four categories where price is shown on a per mole basis (since this is how HEA compositions are typically framed):

- Very high price: $\mathrm{Au}, \mathrm{Sc}$, platinum group metals (50 yr average $>\$ 1,000$ per mole)

- High price: Ag, Ga, Ge, Hf, In, La, Ta (50 yr average $\$ 100$ per mole)

- Intermediate price: $\mathrm{Be}, \mathrm{Bi}, \mathrm{Cd}, \mathrm{Co}, \mathrm{Mo}, \mathrm{Nb}$, rare earth metals, $\mathrm{Sn}, \mathrm{Te}, \mathrm{W}, \mathrm{Y}, \mathrm{Zr}$ (50 yr average $\sim \$ 5$ per mole) 
- Low price: $\mathrm{Al}, \mathrm{Cr}, \mathrm{Cu}, \mathrm{Fe}, \mathrm{Li}, \mathrm{Mg}, \mathrm{Mn}, \mathrm{Ni}, \mathrm{Pb}, \mathrm{Sb}, \mathrm{Si}, \mathrm{Ti}, \mathrm{V}, \mathrm{Zn}$ (50 yr average $\$ 0.5$ per mole)

One way to consider the domain of HEAs by economic constraint is to systematically calculate all possible price combinations for any hypothetical equimolar alloy, in comparison with incumbent alloys. We have conducted that combinatorial investigation, the results of which are summarized in Figure 1. Figure 1a presents the range of alloy price as a function of number of elements $(\mathrm{N})$ in an alloy considering the price categorization above (only $\mathrm{Sc}, \mathrm{Pd}$ and $\mathrm{Ru}$ are included from the very high price category). For $\mathrm{N}$ ranging from 1 to 6 , we calculate an equimolar alloy for all possible combinations of elements, and for each $\mathrm{N}$ we generate the box and whisker plots that show (from bottom up) the 10th, 25th percentile, median, 75th and 90th percentiles of the full distribution of calculated alloy prices.

There are several interesting trends revealed in Figure 1a. First, we note that the median price of alloys increases as the number of constituents rises, by about an order of magnitude by the time a six-component system is reached; mixing elements raises the average price because there is a higher likelihood of a combination including an element from the higher price groups. This suggests that if alloy design is conducted without considering price, the resulting HEAs are likely to be expensive compared with even current specialty metals. However, the lower tails of the curves in this Figure offer a more optimistic view, as some equimolar combinations even out to $\mathrm{N}=6$ exhibit prices below the median $\mathrm{N}=2$ price, with values near the "intermediate" price range as defined above.

Second, as the alloy complexity level rises, the spread of possible alloy prices drops considerably, from almost five orders-of-magnitude at $N=1$ to about two by $N=6$. Diversification of the elemental mix thus tends to narrow the tails of the distribution. This trend is examined in more detail in Figure $1 \mathrm{~b}$, which shows at which number of constituents a highly priced element has to participate in a finished alloy to have its cost "diluted" by the other elements in the system to become cost competitive with other specialty alloys. For a simple set of benchmarks, we use current market prices for $\mathrm{Ni}$ - and Ti- based alloys, as lower bounds on the more costly advanced alloys. Prices for incumbent alloys were obtained from Granta Design's CES selector [12] and converted to a per molar basis and averaged for comparison. We explicitly compare these incumbent alloy prices to the price-weighted mole fraction for each element (the mole fraction, and therefore price, decreases as the number of constituents increases). Clearly, there are significant limitations of final alloy cost based on the elements that are being considered for HEA systems. We can see that even Ta, which has been considered in several refractory HEA works, needs to be used in a cocktail of 15 constituents (equimolar) to achieve cost parity with Ti-based alloys. By the same token, virtually any HEAs that consider $\mathrm{Au}, \mathrm{Hf}, \mathrm{Ge}$, In, Sc or platinum group metals ( $\mathrm{Ir}, \mathrm{Pd}, \mathrm{Pt}, \mathrm{Rh}$, and $\mathrm{Ru}$ ) will face considerable challenges in competing with incumbent alloys and will have to, therefore, demonstrate extraordinarily significant performance improvements. 


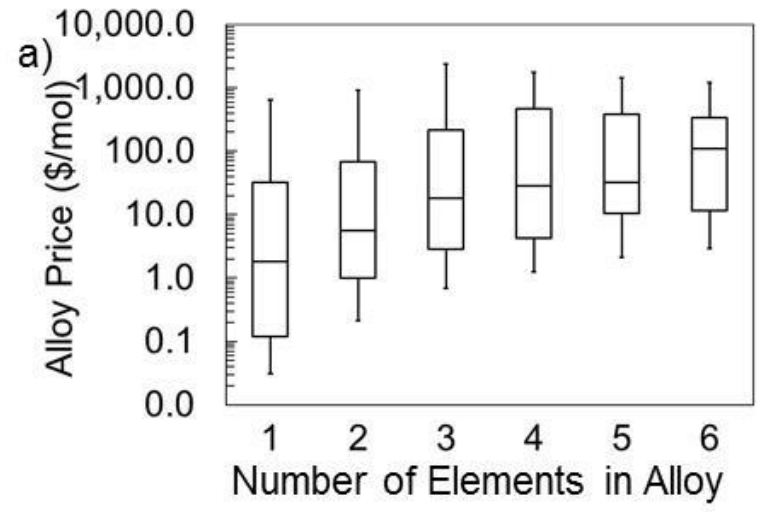

\begin{tabular}{|l|c|c|}
\hline Element & $\begin{array}{l}\text { Av. Ni-based } \\
(\$ 1.70 / \text { mol })\end{array}$ & $\begin{array}{l}\text { Av. Ti-based } \\
(\$ 3.14 / \mathrm{mol})\end{array}$ \\
\hline $\mathrm{Te}$ & 8 & 5 \\
\hline $\mathrm{Ga}$ & 15 & 8 \\
\hline $\mathrm{Ag}, \mathrm{Ta}$ & 30 & 15 \\
\hline $\mathrm{In}, \mathrm{Hf}$ & 50 & 25 \\
\hline $\mathrm{Ge}$ & 80 & 40 \\
\hline $\mathrm{Ru}$ & 300 & 200 \\
\hline $\mathrm{Ir}, \mathrm{Pd}$ & 1000 & 600 \\
\hline $\mathrm{Au}, \mathrm{Pt}, \mathrm{Rh}, \mathrm{Sc}$ & $>3000$ & $>1500$ \\
\hline
\end{tabular}

Figure 1. Price analysis a) range in alloy price in $(\$ / \mathrm{mol})$ as number of elements increases (including Pd, Ru and Sc from the very high price group). Box and whisker from bottom up shows $10^{\text {th }}, 25^{\text {th }}$ percentile, median, $75^{\text {th }}$ and $90^{\text {th }}$ percentile. b) Minimum number of elements necessary to be economically competitive with $\mathrm{Ni}$ and Ti-based alloys. Full price list in $\$ / \mathrm{mol}$ shown in the supplemental information.

Conversely, alloys containing $\mathrm{Mo}, \mathrm{Nb}, \mathrm{Bi}$, or $\mathrm{Sn}$ fall into the range of $\mathrm{Ni}$ or Ti-based alloys (between $\$ 1$ and $\$ 5 / \mathrm{mol}$ ) for at least 5 element HEAs. Alloys containing these elements in equimolar proportions would have challenges competing economically with less expensive advanced alloys (than $\mathrm{Ni}$ and Ti-based) without significant performance improvements. The practicality of working with $\mathrm{N}$ equimolar constituents becomes much more dubious from both a processing standpoint as well as a supply chain perspective as $\mathrm{N}$ rises. On the other hand, Co, Cd, W, Zr and all the elements within the low price group listed above appear price competitive even in 5 or less constituent HEAs, all other things being equal.

\section{Price volatility}

The economic analysis in Figure 1 was based on average 2014 price, but metal prices change significantly over time, so we also present an assessment of price volatility from 1964-2014. Volatility is of interest because if we consider that we would need a greater fraction of a wider variety of elements in HEA, more of the total price could be impacted by a particularly price volatile constituent. Previous work has explored volatility of base metals (because they are of high volume) and precious metals (because they are high value) [13-16]. There have been limited investigations of the cross-correlation of metals prices except for examples of secondary versus primary materials [17]. The method for determining price volatility is one established by the economic research community, based on the standard deviation of the time series of price [18-20], i.e. Volatility $=\sqrt{\sum_{t=1}^{T} \frac{\left(p_{t}-\bar{p}\right)^{2}}{(T-1) \bar{p}^{2}}}$, where $p_{t}$ is the log price in year t over the time period $\mathrm{T}$, and the standard deviation is normalized by the mean of price, $\bar{p}$. Here we consider $\mathrm{T}=5$ and 10 year time periods.

To evaluate the price volatility of any possible HEA, we compare variation in materials price over time for individual elements and then show how their volatility manifests in alloy form at equimolar concentration. 

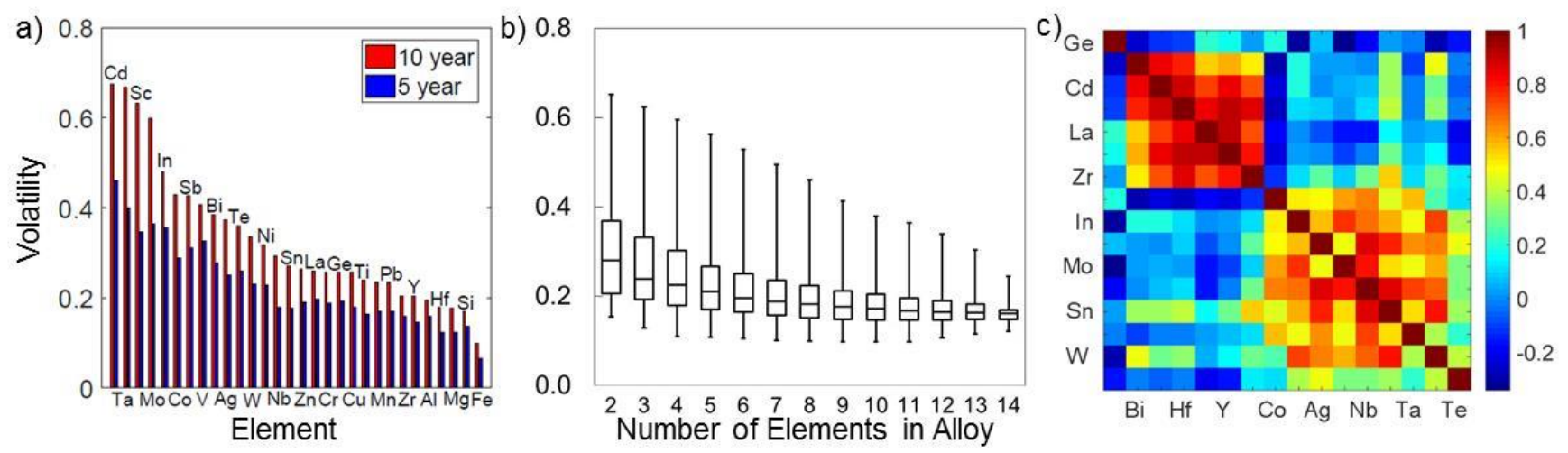

Figure 2. Price volatility assessment. a) Elemental price volatility over 5 year time frame (blue) and 10 year time frame (red) ordered by 10 year decreasing price volatility. b) Alloy-based price volatility over 10 year time frame shown with increasing number of elements in an alloy (all possible combinations, equi-atomic). Box and whisker from bottom up shows minimum, $25^{\text {th }}$ percentile, median, $75^{\text {th }}$ percentile and maximum c) price correlation heat map for intermediate and high price groups, red indicates highest positive correlation.

Mitigating price volatility of a particular element in an alloy provides an interesting opportunity to either distribute or concentrate risk depending on whether there is correlation between elemental prices as well as the magnitude of the volatility. Figure $2 \mathrm{a}$ shows the individual elemental price volatility ordered from high to low volatility (for 10 year values) for 30 elements (elements labeled above and below the bars). In all cases the 10 year volatility is higher than the 5 year equivalent. We see that for the 5 year average the highest volatilities are for $\mathrm{Cd}$ and $\mathrm{Ta}$ at $45 \%$ and $40 \%$, respectively; the latter has seen increased use in electronic applications in recent decades. Fe has the lowest volatility at less than $10 \%$ ( 5 year).

Figure $2 \mathrm{~b}$ shows the 10 year range in price volatility for alloys containing all metals in the intermediate and high price groups, ranging from alloys with $\mathrm{N}=2$ to 14 elements. The resulting trend is an optimistic one for HEAs: there is a general reduction of price volatility with $\mathrm{N}$. This arises from the combination of some pairs of elements having negative correlation, and the 'dilution' from adding less price-volatile elements. As seen also in Figure 2b, increasing $\mathrm{N}$ on average reduces price volatility in the high and intermediate price metal group.

Figure 2c presents a correlation analysis, constructed for sixteen metals. The $i, j$ entry of the correlation matrix is the Pearson correlation coefficient between the price time series of metal $i$ and metal $j$, and the color in each block indicates the value of the corresponding coefficient [21]. The colors illustrate elements that, when included together in a single HEA, would work to increase price volatility (in red) and those that would tend to offset one another's volatility (in blue). We see that the most negatively correlated materials were Co with $\mathrm{Bi}$, as well as Ge with either Mo or In. These elements would help to reduce volatility most if considered together. Those element pairs whose historic price volatility are positively correlated (and therefore more subject to high volatility if both are included in the final alloy) tend to involve $\mathrm{Y}, \mathrm{Hf}, \mathrm{Zr}$ and $\mathrm{Cd}$. While some positive correlations between elements could be challenging, generally volatility is helped by diversifying the constituents of an alloy, particularly when more of the material will be used.

\section{Materials availability}


Some metals may not be readily available in the future, and this availability risk has recently become of great interest in exploring material use and design $[22,23]$. This risk depends on a variety of factors including geological abundance, substitution potential, geopolitical concentration, government stability and economic policy [24]. Various studies have described availability risk, or 'criticality', for decision makers at (and across) different organizational levels, from company level, to government level up to a global level [24-27].

To provide an example of a materials availability risk for HEAs we look at the geopolitical supply concentration using the Herfindahl-Hirschman Index (HHI) [28], and further consider whether a given constituent element is mined as a byproduct. $\mathrm{HHI}$ is calculated based on production for each element calculated from USGS commodity statistics following the approach used by others, $\mathrm{HHI}=\sum_{i}^{M} s_{i}^{2}$ where $\mathrm{M}$ is the total number of countries involved and $S_{i}$ is the percent market share of country $i$ compared to world production. Production information was obtained from the USGS minerals yearbook as well as the British Geological Survey (BGS) [11]. The U.S. Department of Justice and the Federal Trade Commission have designated markets as 'not concentrated' when $\mathrm{HHI}<1500$, 'moderately concentrated' when the HHI lies between 1500 and 2500, and 'highly concentrated' when $\mathrm{HHI}>2500[22,23]$; lower $\mathrm{HHI}$ is preferred. Figure 3a shows the elemental-HHI results for 30 elements, calculated according to the equation above and colored to distinguish the concentration categories as described above. Because of data limitations Hf's HHI is calculated from $\mathrm{Zr}$ production, and Sc's $\mathrm{HHI}$ is estimated using rare earth element data. We see that many of the elements under consideration for HEAs may be considered highly geopolitically concentrated, which may be of significant concern to manufacturers. For those elements that are more concentrated and where production volumes are low, this may be of further concern. Examples of these elements include $\mathrm{W}, \mathrm{Nb}, \mathrm{V}$, and Sc as they have small total production volumes and high $\mathrm{HHI}$.

There are at least two ways we might interpret HHI for HEA candidates, at both the elemental and alloy level, and we consider these in turn in what follows.

First, if HEA producers find it difficult to develop a consistent supplier for even one element in any quantity, this might increase the risk of the whole alloy proposition. A producer might view the availability as being limited by the highest $\mathrm{HHI}$ element in the HEA; the relevant parameter for evaluating different HEAs would therefore be the maximum $\mathrm{HHI}$ of any of its constituents, and the data in Figure $3 a$ are sufficient to compare the viability of different alloys based on the highest $\mathrm{HHI}$ constituent alone. 


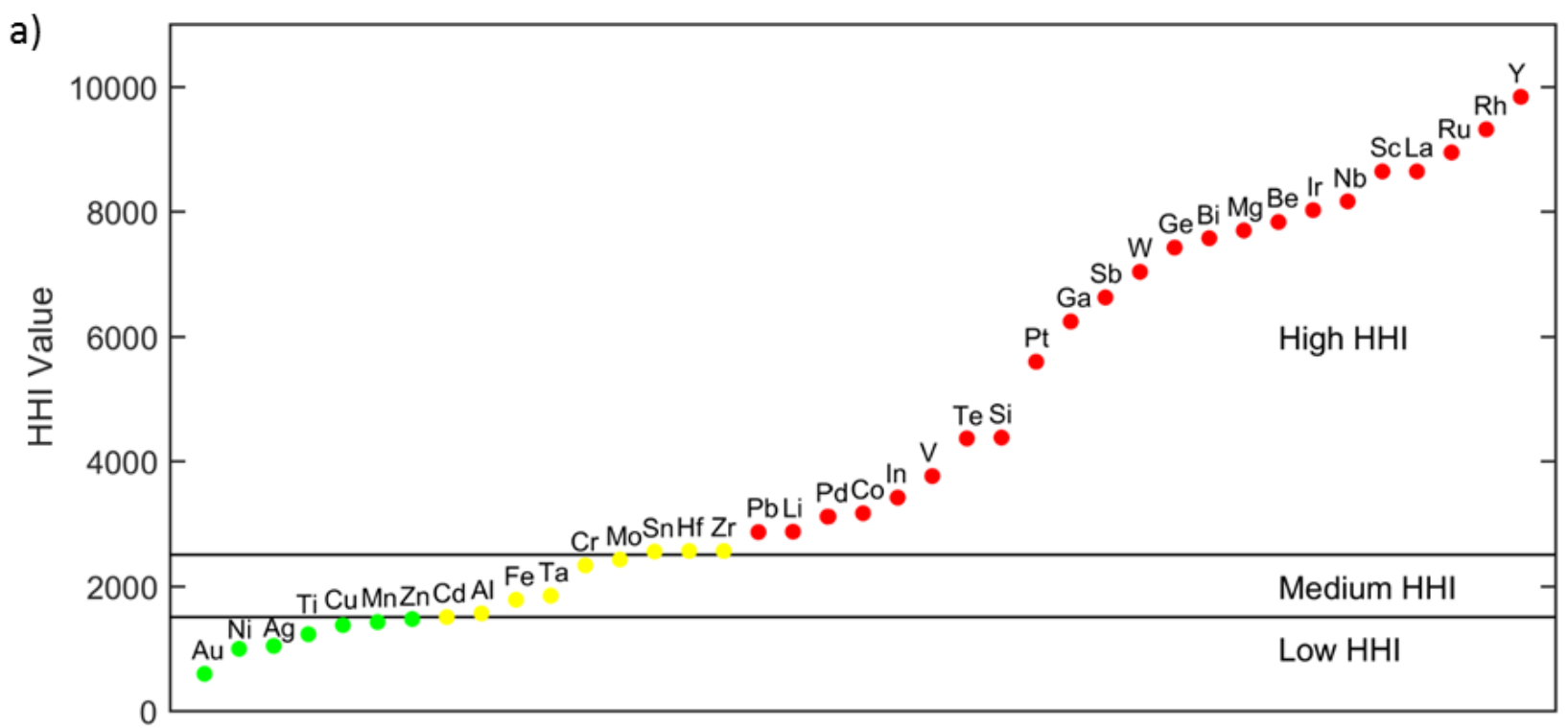

\section{b)}

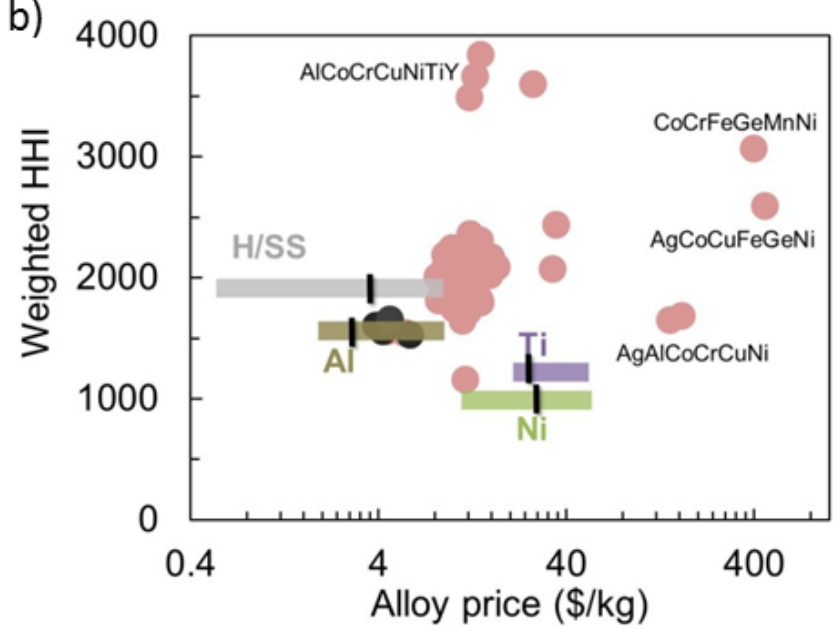

c)

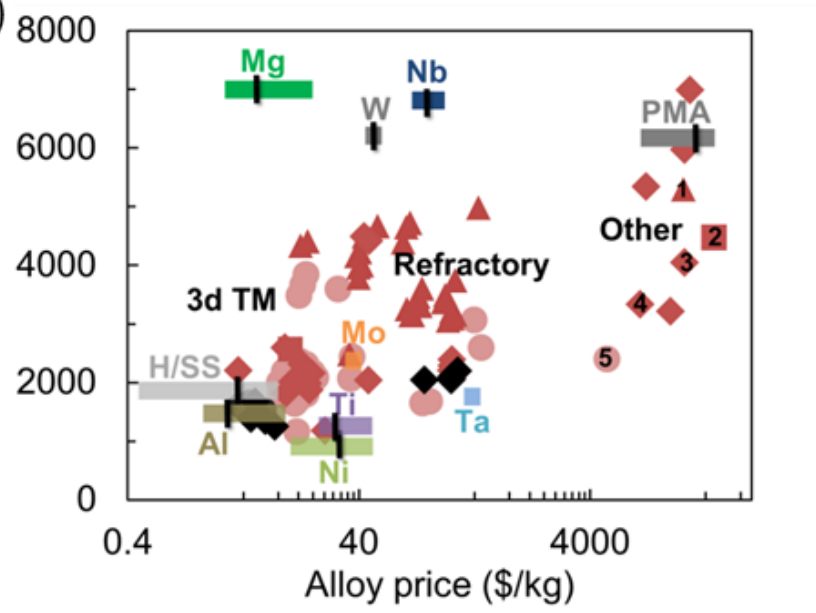

Figure 3. a) Herfindahl-Hirschman Index (HHI) by element. Green considered not geopolitically concentrated, yellow of moderate geopolitical concentration and red high concentration. b) Alloy price $(\$ / \mathrm{kg})$ versus weighted alloy supply concentration for several base-alloy systems as well as HEAs proposed in the literature (H/SS = high strength steel and stainless steel). Length of bar for base alloys includes range in price, black line is average. c) Alloy price versus weighted HHI (y-axis label shared with b) for expanded set of alloy systems. Differentiates 125 HEAs between 3d transition metal (3d TM, circles), refractory (triangles), light metal (squares) and other alloys (diamonds) (as described by [1]). Red shapes indicate alloys that contain at least one element with high HHI versus black

dots, which do not. A few alloys are labelled for reference on the right hand side 1: NbScTiZr, 2: AlLiMgScTi, 3: MoPdRhRu, 4: CulrNiPdPtRh, and 5: CoCrFeNiPd. Full list shown in the supplemental information.

On the other hand, we have calculated a compositionally-weighted average $\mathrm{HHI}$, which attaches relevance to the quantity of each constituent, i.e., obtaining more of a more geopolitically concentrated material would be more challenging than obtaining a smaller amount. In this case, those elements with high $\mathrm{HHI}$ in the alloy mix are 'diluted' by the lower $\mathrm{HHI}$ of the other alloying elements, so elemental $\mathrm{HHI}$ values are used to calculate weighted $\mathrm{HHI}$ production based on the fraction of each element in the chemical formula. These weighted-HHI values are considered in $3 \mathrm{~b}$ and $3 \mathrm{c}$. 
Figure $3 b$ and $c$ plot several HEAs proposed in the literature by average alloy price on the $x$-axis and mole weighted-HHI on the $\mathrm{y}$-axis, compared to conventional alloys. We focus first on Figure $3 b$, which limits the discussion to the family of HEAs that nominally compete with conventional alloy systems, including Al alloys (shown with a brown bar), $\mathrm{Ti}$ alloys (in purple), $\mathrm{Ni}$ alloys (in light green), and stainless/high strength steel (denoted $\mathrm{H} / \mathrm{SS}$ and shown in grey). For each of these classes of alloys, the average price is denoted with a black bar. The red dots in Figure $3 \mathrm{~b}$ represent proposed HEAs indicate alloys that contain at least one element with high $\mathrm{HHI}$ (high geopolitical supply concentration), versus black dots which indicate systems that do not.

A first observation from Figure $3 b$ is that the majority of HEA candidates exceed both average alloy price and supply concentration as compared with the $\mathrm{Al}$ and $\mathrm{H} / \mathrm{SS}$ commodity alloys on the market today, by perhaps a factor of two on average. These alloys therefore need to offer a performance advantage high enough to not only justify the increased price, but also the increased supply risk. Some of the HEA candidates considered in the literature well exceed even the price of common $\mathrm{Ti}$ and $\mathrm{Ni}$ systems, because of the presence of $\mathrm{Ag}$ or Ge. Our analysis does not identify any proposed HEA system which has a lower HHI than Ni-based alloys. However, looking specifically at the black dots in Figure 3b, we see a handful of HEA compositions that are both low in HHI and in price. These alloys are from references [29-43] and include variants in composition for the following alloy systems: AlCrCuFeMnNi, AlCrCuFeNi, AlCrFeNi, AlCrCuFeNiTi, AlCrFeMnNi, AlFeMoNi, CrCuFeMnNi, CrFeMnNi, and CrFeMnNiTi.

Figure $3 c$ presents the same data as Figure $3 b$, but now expands both axes to consider a broader set of proposed HEAs and their comparators. In particular, in Figure $3 c$ we delineate a subset of the alloy families described by Miracle and Senkov [1] including 3d transition metals (3d TM shown with circles), refractory HEAs (triangles), light metal alloys (squares) and other HEAs (diamonds, including those that contain precious metals). In this plot additional relevant comparators have been added, namely the refractory metals $\mathrm{Mo}, \mathrm{Ta}, \mathrm{W}, \mathrm{Nb}$ (for comparison with the refractory HEAs), precious metal alloys (denoted PMA, for comparison with high price "other" HEAs) and Mg alloys (for comparison with the HEAs containing 3d transition metals, labelled 3d TM and light metals).

Figure $3 c$ indicates that the refractory HEA systems are generally competitive with the higher HHI comparators, $\mathrm{W}$ and $\mathrm{Nb}$, on price, and even better in weighted $\mathrm{HHI}$. This is an example of the power of dilution in HEAs that use less of those high HHI elements. This dilution effect is evident for both the 3d TM HEAs and the 'other' HEAs as well, which on average attain similar pricing to $\mathrm{Mg}$ and precious metal alloys, respectively, but which are of lower $\mathrm{HHI}$ by virtue of the inclusion of less supply concentrated constituents. However, most of these alloys are labelled with red points, meaning that they contain high $\mathrm{HHI}$ constituents, which may involve high supply risk. When this consideration is taken into account, we can conclude generally that the vast majority of the current HEA systems being explored would face significant challenges competing with incumbent alloys, and therefore must have clear performance advantages along several dimensions. A set of interesting exceptions to this statement is provided by the black diamonds in Fig. 3c, which are cost competitive with $\mathrm{Nb}$ and $\mathrm{Ta}$, but are of potentially lower geopolitical supply concentration. These alloys are AlCrTaTiZr, BeCuHfNiTiZr, BeCuHfTiZr, CuFeHfTiZr, and CuHfNiTiZr [44, 45]. We note that $\mathrm{Hf}$ and $\mathrm{Zr}$ are on the border between medium and high $\mathrm{HHI}$.

Finally, there is another materials availability consideration not fully reflected in the discussion above. If the element of interest is mined as a byproduct of another metal system, as reported by Nassar [46], it carries 
additional supply risk because of its dependency on the market of the parent metal system. In terms of this byproduct status, the elements that could be of concern are $\mathrm{Bi}, \mathrm{Co}, \mathrm{Ga}, \mathrm{Ge}, \mathrm{In}, \mathrm{Mo}, \mathrm{Sb}, \mathrm{Se}, \mathrm{Ta}$, and Te.

\section{Recyclability}

HEA systems have occasionally been described as "more recyclable" than conventional alloys in some of the current literature; however, this assertion has not been justified with specific analysis to date. From an economic perspective, metals that are more expensive in an HEA system might drive interest in recycling. Recycling rates for minor metals are typically rather low because they are used in small amounts. If HEA systems require a much larger amount of those metals in a single application, this would give recyclers better incentive to recover these materials. Based on this assertion, it is important to consider which existing recycling stream an HEA could enter. Previous work on the thermodynamics of recycling provide comprehensive analysis regarding the fate of impurity elements in recovered metal in the gas, slag or metal phase, depending on the Gibbs free energy of the impurity reaction, the activity coefficient of the oxidation product, and the economics of recovery [47]. If impurity elements remain in the metal phase their removal requires subsequent post-processing and may even be a significant detriment to final properties (examples include copper or tin in steel). This multi-stage recovery and potential for contamination is a significant challenge for many recycling systems, most predominantly in aluminum recycling.

If we consider the extractive metallurgical processes for typical carrier metals, we can provide insight as to where in the recycling system HEAs might be introduced. The major processes to consider include those for iron/steel, aluminum, copper, and zinc/lead. While there are others such as magnesium or stainless steel, those markets are much smaller and not considered here. The thermodynamic and physical compatibility of HEA constituents with these metallurgical processes is essential for their economic separability. Table 1 considers several elements proposed for use in HEAs as a function of these essential processes. Here the red and yellow colors denote potentially significant separation challenges, being less separable from the base metal of the process, and more (yellow) or less (red) benign to the properties of the recycled base metal. The green combinations show the nominally plausible introductions. These data are from thermodynamic analyses in the literature accounting for distribution of elements among phases such as gas, slag, and metal considering reactions such as oxidation or volatilization [47-49]. For example, by examining an Ellingham diagram for the species of interest, which shows the relative Gibbs free energies for equilibrium oxidation/reduction reactions, we can understand the relative energy required to remove an impurity from a particular carrier melt. These published analyses also account for other thermodynamic parameters, such as the temperature, activity coefficients of the impurity in the metals, and oxygen partial pressure. We have also included information regarding metals compatibility from the literature, such as the case for $\mathrm{Cu}$ in steel mentioned above [48]. These existing data sources were combined to establish the color coding below. Recyclability is a very complex issue, whose full exploration is outside the scope of this contribution, but we provide a preliminary screening in Table 1.

Table 1. Material compatibility for proposed elements with various carrier metal processing routes. Yellow denotes that the element would likely be lost in a single stage recovery process (requiring subsequent post-recovery) but without determent to the carrier metal; Red elements cannot be economically recovered and are potentially detrimental to carrier metal. Green indicates that element is likely compatible and can be recovered in subsequent, currently economic, processing. 


\begin{tabular}{|l|l|l|l|l|}
\hline & \multicolumn{3}{|c|}{ Extractive metallurgical processes } \\
\hline & Iron/Steel & Aluminum & Copper & Zinc/Lead \\
\hline $\mathrm{Ag}, \mathrm{Au}, \mathrm{Pt}$ & & & & \\
\hline $\mathrm{Al}$ & & & & \\
\hline $\mathrm{Bi}, \mathrm{Cd}$ & & & & \\
\hline $\mathrm{Co}, \mathrm{Ga}, \mathrm{Mo}, \mathrm{Ni}, \mathrm{Ta}$ & & & & \\
\hline $\mathrm{Cr}$ & & & & \\
\hline $\mathrm{Cu}$ & & & & \\
\hline $\mathrm{Fe}$ & & & & \\
\hline $\mathrm{Mg}, \mathrm{Mn}, \mathrm{Y}, \mathrm{Nb}, \mathrm{Ti}, \mathrm{V}, \mathrm{W}$ & & & & \\
\hline $\mathrm{Pd}$ & & & & \\
\hline $\mathrm{Sc}$, Rare earth, $\mathrm{Hf}, \mathrm{Zr}$ & & & & \\
\hline $\mathrm{Zn}$ & & & \\
\hline
\end{tabular}

We see that many elements under consideration could present a challenge in iron/steel and aluminum recovery processes. In the case of the yellow boxes above, having larger portions of the constituent present may be an advantage for economic recovery based on economies of scale, however the red shaded combinations above could present significant challenges. Another broad obstacle to recovery of multi-constituent systems is found in the seemingly simple challenge of collecting and consolidating these materials. Scrap collectors are often not interested in small volumes that might be generated even in a manufacturing context. These materials may not be well separated from more conventional alloys and therefore lose their 'identity' as materials with a larger fraction of more valuable elements.

One potentially optimistic message in Table 1 is that for the first HEAs to reach the market, it may be plausible to contemplate a recycling path through the existing copper or zinc/lead based processes in the market today. However, these processes are the least geographically distributed, so would require significant volumes to warrant the economics of collection. There are nominal barriers to recycling through copper or zinc/lead based processes for commonly used HEA elements such as $\mathrm{Cr}$, Al, and even Fe (which is typically magnetically separated before materials enter $\mathrm{Al}, \mathrm{Cu}$ or $\mathrm{Zn} / \mathrm{Pb}$ systems). To avoid future sustainability challenges, the compatibility of these elements in current recycling infrastructure should be considered. Given their small initial volumes and the relative lack of compatibility of the majority of the commonly used elements, we conclude that HEAs do not present as initially "more recyclable".

\section{Conclusion}

Based on the increased interest in HEA development over the past decade and rising interest going forward, we urge the metallurgical community to incorporate alloying screening principles based on the economic and resource use consequences of element selection. There are some elements with significant concerns along these axes, which only increase the technical performance benefits that would be necessary to drive adoption of an HEA over conventional alloys. From this initial screening we conclude that designers might avoid elements of clear concern from an economic and resource availability perspective including precious metals, platinum group metals, Sc, Ge, Te, and Ta. And for HEAs competing with high strength steels, elements such as Co, V, or Zr might 
additionally present some challenge. More positive are the effects of multicomponent formulations in terms of potentially mitigating price volatility and in some cases, supply concentration concerns.

While the present analysis has led to some clear and actionable principles for alloy screening and design, additional analysis along these lines will clearly be needed as the HEA field matures. For example, a dynamic exploration of the metrics discussed above, in which evolving market share is evaluated as expected HEA applications become clear, will be needed. Furthermore, we have only considered materials price in our analysis here, but in some cases significant additional processing cost would be expected. Manufacturing cost modeling as an input for alloy screening and development is thus viewed as a vital component in the search for viable HEAs.

If a proper balance of improved properties and economic viability can be established, HEAs may expand the role that metal alloys play in a variety of applications. However, in order to establish such a value proposition, HEA development should consider aspects of design beyond improvement in technical performance at as early a stage as possible, lest the excitement over their properties be dashed against the reality of their technological viability.

\section{Acknowledgements}

The authors thank A. Boros and W. Kong for their initial data gathering efforts. The authors would like to acknowledge funding from the National Science Foundation Award \#1605050, CBET program that provided partial support to make this work possible.

\section{References}

[1] D.B. Miracle, O.N. Senkov, Acta Materialia 122 (2017) 448-511.

[2] F.J. Baldenebro-Lopez, J.M. Herrera-Ramirez, S.P. Arredondo-Rea, C.D. Gomez-Esparza, R. Martinez-Sanchez, Journal of Alloys and Compounds 643 (2015) S250-S255.

[3] F. Zhang, C. Zhang, S.L. Chen, J. Zhu, W.S. Cao, U.R. Kattner, Calphad-Computer Coupling of Phase Diagrams and Thermochemistry 45 (2014) 1-10.

[4] M.C. Troparevsky, J.R. Morris, M. Daene, Y. Wang, A.R. Lupini, G.M. Stocks, Jom 67(10) (2015) 2350-2363.

[5] L.A. Dominguez, R. Goodall, I. Todd, Materials Science and Technology 31(10) (2015) 1201-1206.

[6] Y.Y. Chen, T. Duval, U.D. Hung, J.W. Yeh, H.C. Shih, Corrosion Science 47(9) (2005) 2257-2279.

[7] O.N. Senkov, G.B. Wilks, D.B. Miracle, C.P. Chuang, P.K. Liaw, Intermetallics 18(9) (2010) 1758-1765.

[8] M.C. Gao, C.S. Carney, A.N. Dogan, P.D. Jablonksi, J.A. Hawk, D.E. Alman, Jom 67(11) (2015) 2653-2669.

[9] B. Cantor, Entropy 16(9) (2014) 4749-4768.

[10] M.F. Ashby, D. Cebon, Le Journal de Physique IV 3(C7) (1993) C7-1-C7-9.

[11] T.D. Kelly, G.R. Matos, D. Buckingham, C. Difrancesco, K. Porter, C. Berry, M. Crane, T. Goonan, J. Sznopek, Historical statistics for mineral and material commodities in the United States, US Geological Survey Reston, VA2005.

[12] M. Ashby, A. Miller, F. Rutter, C. Seymour, U. Wegst, The CES EduPack Eco Selector-Background Reading, Granta Design, Cambridge, UK, 2009.

[13] C. Brunetti, C.L. Gilbert, Resources Policy 21(4) (1995) 237-254.

[14] M.C. Roberts, Resources Policy 34(3) (2009) 87-102.

[15] G. Dooley, H. Lenihan, Resources Policy 30(3) (2005) 208-217.

[16] C. Watkins, M. McAleer, Applied Financial Economics 16(12) (2006) 853-880. 
[17] I.M. Xiarchos, J.J. Fletcher, Resources, Conservation and Recycling 53(12) (2009) 664-673.

[18] M. Redlinger, R. Eggert, Resources Policy 47 (2016) 69-77.

[19] J.P. Ferderer, Journal of macroeconomics 18(1) (1997) 1-26.

[20] H. Bessembinder, P.J. Seguin, The Journal of Finance 47(5) (1992) 2015-2034.

[21] C. Spearman, British Journal of Psychology, 1904-1920 3(3) (1910) 271-295.

[22] M.W. Gaultois, T.D. Sparks, C.K. Borg, R. Seshadri, W.D. Bonificio, D.R. Clarke, Chemistry of Materials 25(15) (2013) 2911-2920.

[23] L. Ghadbeigi, J.K. Harada, B.R. Lettiere, T.D. Sparks, Energy \& Environmental Science 8(6) (2015) 1640-1650.

[24] T. Graedel, E. Harper, N. Nassar, P. Nuss, B.K. Reck, Proceedings of the National Academy of Sciences 112(14) (2015) 4257-4262.

[25] R. Eggert, A. Carpenter, S. Freiman, T. Graedel, D. Meyer, T. McNulty, B. Moudgil, M. Poulton, L. Surges, E. Eide, National Research Council (US) (2008).

[26] P.d.N.U.p. I'environnement, M. Buchert, D. Schüler, D. Bleher, Critical metals for future sustainable technologies and their recycling potential, UNEP DTIE; Öko-Institut2009.

[27] T.E. Graedel, R. Barr, C. Chandler, T. Chase, J. Choi, L. Christoffersen, E. Friedlander, C. Henly, C. Jun, N.T. Nassar, Environmental science \& technology 46(2) (2012) 1063-1070.

[28] O.C. Herfindahl, Concentration in the steel industry, Columbia University., 1950.

[29] F. Otto, Y. Yang, H. Bei, E.P. George, Acta Materialia 61(7) (2013) 2628-2638.

[30] G.-Y. Ke, S.-K. Chen, T. Hsu, J.-W. Yeh, Ann. Chim. Sci. Mat. 31(6) (2006) 669-683.

[31] M.-H. Tsai, K.-Y. Tsai, C.-W. Tsai, C. Lee, C.-C. Juan, J.-W. Yeh, Mater. Res. Lett. 1(4) (2013) 207-212.

[32] H.-Y. Chen, C.-W. Tsai, C.-C. Tung, J.-W. Yeh, T.-T. Shun, C.-C. Yang, S.-K. Chen, Ann. Chim. Sci. Mat. 31(6) (2006) 685-698.

[33] M. Chen, Y. Liu, Y.X. Li, X. Chen, Acta Metall. Sin. 43(10) (2007) 1020-1024.

[34] S.-T. Chen, W.-Y. Tang, Y.-F. Kuo, S.-Y. Chen, C.-H. Tsau, T.-T. Shun, J.-W. Yeh, Mater. Sci. Eng. A 527(21-22) (2010) 5818-5825.

[35] Y. Dong, Y. Lu, J. Kong, J. Zhang, T. Li, J. Alloys Compd. 573 (2013) 96-101.

[36] S. Guo, C. Ng, C.T. Liu, J. Alloys Compd. 557 (2013) 77-81.

[37] S. Guo, C. Ng, J. Lu, C.T. Liu, J. Appl. Phys. 109(10) (2011) 103505.

[38] P. Jinhong, P. Ye, Z. Hui, Z. Lu, Mater. Sci. Eng. A 534 (2012) 228-233.

[39] C.-P. Lee, C.-C. Chang, Y.-Y. Chen, J.-W. Yeh, H.-C. Shih, Corros. Sci. 50(7) (2008) 2053-2060.

[40] J.-H. Pi, Y. Pan, L. Zhang, H. Zhang, J. Alloys Compd. 509(18) (2011) 5641-5645.

[41] Y.Y. Du, Y.P. Lu, T.J. Li, T.M. Wang, G.L. Zhang, Mater. Res. Innov. 15(2) (2011) 107-110.

[42] B. Ren, Z.X. Liu, D.M. Li, L. Shi, B. Cai, M.X. Wang, J. Alloys Compd. 493 (2010) 148-153.

[43] Z. Wu, H. Bei, Mat. Sci. Eng. A 640 (2015) 217-224.

[44] C.-H. Lai, S.-J. Lin, J.-W. Yeh, S.-Y. Chang, Surface and Coatings Technology 201(6) (2006) 3275-3280.

[45] L. Ma, L. Wang, T. Zhang, A. Inoue, Mater. Trans. JIM 43(2) (2002) 277-280.

[46] N. Nassar, T. Graedel, E. Harper, Science advances 1(3) (2015) e1400180.

[47] T. Hiraki, O. Takeda, K. Nakajima, K. Matsubae, S. Nakamura, T. Nagasaka, Science and Technology of Advanced Materials (2016).

[48] E. Worrell, M. Reuter, Handbook of recycling, Elsevier, Amsterdam, 2014.

[49] K. Nakajima, O. Takeda, T. Miki, K. Matsubae, T. Nagasaka, Environmental Science \& Technology 45(11) (2011) 4929-4936. 